\title{
Archaeological Perspectives in Information Science
}

\author{
Isto Huvila \\ Department of ALM, Uppsala University, Sweden. \\ isto.huvila@abm.uu.se \\ Michael Olsson \\ University of Technology Sydney, Australia. Email: \\ michael.olsson@uts.edu.au \\ Ixchel M. Faniel \\ OCLC Research, USA. fanieli@oclc.org
}

\author{
Marija Dalbello \\ School of Communication and Information, Rutgers \\ University, USA. dalbello@rutgers.edu \\ Costis Dallas \\ Faculty of Information, University of Toronto, Canada. \\ costis.dallas@utoronto.ca
}

\begin{abstract}
Archaeology is a domain that has intersections with information science and technology research both as an empirical domain of investigation and as a perspective to inquire into how people interact with information. The aim of this panel is to highlight this interdisciplinary nexus of diverse engagements and to explicate how archaeology has informed and could inform information science research and practice in the future, and how empirical information science research on archaeological practices has enhanced our understanding of both archaeological work and human information behavior and practices in general.
\end{abstract}

\section{KEYWORDS}

archaeology, information science, information practices, archives

\section{INTRODUCTION}

Information science has often been described as an interdisciplinary domain. It brings together a diversity of insights from widely different disciplines to create new knowledge and enhance theoretical and practical understanding about how information influences our lives. This panel digs deeper into an intriguing interdisciplinary nexus of engagements between information science and archaeology to highlight 1) how archaeology, archaeological methods and archaeological metaphors have informed and could inform information science research and practice in the future, 2) how empirical information science research on archaeological practices has enhanced our understanding of both archaeological work and human information behavior and practices in general and 3) what implications these areas of research have had and could have on the advancement of research and practice in the information science and technology domains. The panelists represent information science researchers who have conducted empirical research on archaeological information

$80^{\text {th }}$ Annual Meeting of the Association for Information Science \& Technology, Washington, DC, VA | Oct. 27-Nov. 1, 2017

Authors Retain Copyright practices and knowledge production and have used archaeologically inspired methods and theory in their work.

The relevance of discussing the links between information science and archaeology relates to the increasing societal significance of the cultural heritage domain around the globe, especially in Europe, where it has been one of the key areas of cooperation for a long time. More recently, the link between information science and archaeology has become more significant, given the integration of a rapidly increasing migrant population. In addition, a better understanding of archaeological information work has become critical for managing and exploiting the escalating amounts of archaeological data from current and prior archaeological excavations around the world. From a theoretical and practical perspective, archaeology also is a good example of a cross-disciplinary domain of information use and methodology that engages diverse fields from the humanities to the natural sciences and serves as an interesting showcase of the problems, challenges and opportunities related to inter- and multi-disciplinary domains of information practices. Finally, archaeology has functioned as a powerful metaphor for critical research in information science and technology.

\section{ARCHAEOLOGY IN AND FOR INFORMATION SCIENCE}

Information science and technology research have worked in tandem with archaeology research for several decades. Despite the sporadic rate of the references back and forth, the literature shows a depth and breadth of topics. Archaeologyrelated and archaeological information science research can be roughly divided to three areas: 1) information management-, organization- and retrieval- oriented studies, 2) research on archaeological information practices and 3) archaeological and archaeology-inspired research on information science topics. Moreover, several studies span these lines of research which indicates how archaeology has interested information science and technology researchers and vice versa.

The focus of management-, organization- and retrieval- oriented research has been on the development of theories, methods and practices of archaeological information work. Much of this work has been informed only indirectly by information science but there are some exceptions with links to 
knowledge organization, information management and digital libraries research (e.g., Huvila, 2006; Tudhope et al., 2011; Vlachidis \& Tudhope, 2015; Dallas, 2016b).

The second line of research focuses on information behavior and practices of archaeologists, including studies about archaeological documents, documentation and the sociotechnical aspects of archaeological knowledge production. Studies range from archaeologists' information behavior (e.g., Huvila, 2006), studies of sociotechnical practices in archaeology (e.g., Khazraee, 2013), pervasive digital curation practices in archaeological fieldwork (Dallas, 2015), grey literature (e.g., Seymour, 2009), images (Beaudoin, 2014) and research data (e.g., Faniel et al., 2013; Faniel \& Yakel, 2017) to information and knowledge management practices (e.g., Huvila, 2016a,b) and materiality, especially bodily aspects of archaeological information practices (Olsson, 2016).

In contrast, the third line of research has used archaeology as a method or approach for studying diverse information science topics. Dalbello-Lovric (1999) adopted an archaeological approach in her study of bibliographies and Radford et al., (2012) used Foucault's archaeology of knowledge to investigate the deaccessioning of library collections. Mak (2014) also used it to investigate the practices related to digitization. Although Foucault's archaeology of knowledge may seem relatively popular, Dewey's (2016) findings suggest that the approach has been used less than expected. It also is surprising that media archaeology (Parikka, 2012), a popular approach in media and communication studies has been used rarely in information science and technology research.

\section{LAYOUT OF THE PANEL}

The moderator begins the panel with a 10-minute overview of archaeological and archaeology-related research in information science. Next, each of the four panelists gives a fiveminute lightning talk describing how they have used archaeology as a perspective or a topic of empirical research with a focus on theoretical and empirical insights and implications of working with archaeology as a branch of professional, scholarly activity or as a perspective in the context of the information science research.

After the lightning talks, each panelist takes three minutes to react to their colleagues' presentations, highlighting commonalities and differences in approaches, followed by oneminute future-looking reflections on how to push the current state-of-the-art in their areas of study. During the final 30 minutes, the moderator facilitates a discussion with the audience to reflect on archeology's usefulness as a perspective and topic of empirical research in information science and technology. The panel closes with an invitation and a short round of proposals for future engagements with archaeology both within and beyond information science from the panelists and the audience, including a call for contributions to a forthcoming special issue on the topic of the panel.
The presentations combine two parallel approaches to engage with archaeology in the context of information science research. All presentations explicate practices that are archaeological within the domain of archaeology (Huvila, Olsson, Faniel, Dallas) and simultaneously or alternatively in other contexts such as archives, libraries and museums (Dalbello, Dallas, Huvila, Faniel). At the same time, all presentations highlight empirical and conceptual insights from archaeology-related research pertaining to topics such as embodiment and materiality, trust, sharing and boundaries, information behavior and practices, records and evidence. The presenters will each make a connection of their work to implications to information science pedagogy (teaching and curriculum development).

\section{PANELISTS AND THEIR CONTRIBUTIONS Isto Huvila, Uppsala University}

Isto Huvila presents empirical findings of his research on the documentation of archaeology and archaeological work and the making of archaeological knowledge. The presentation draws both on his earlier and ongoing empirical research on archaeological information work and information management in archaeology. Huvila shows how his empirical research has provided multiple practical and theoretical insights into information work and management research beyond archaeology, including insights into such theoretical concepts as boundary objects, trust and anonymity, and how an empirical archaeological perspective can be useful in explicating information practices in other contexts such as libraries, archives and museums.

Professor Isto Huvila holds the chair in library and information science at the Department of ALM (Archival Studies, Library and Information Science and Museums and Cultural Heritage Studies) at Uppsala University in Sweden and is adjunct professor (docent) in information management at Åbo Akademi University in Turku, Finland. Archaeology has been a long-lasting context of his research that ranges from information and knowledge management, information work, knowledge organization and documentation to social and participatory information practices.

\section{Michael Olsson, University of Technology Sydney}

Michael Olsson describes his study of the information practices of archaeologists in the field based on ethnographic fieldwork at two excavation sites with archaeologists from the University of the Highlands and Island son Orkney, Scotland. The findings demonstrate the centrality of embodied information practices, such as haptic analysis (McGregor, 1999) for archaeologists' sense-making. It suggests that archaeologists learned these embodied practices experientially via a kind of apprenticeship, as described by Lave \& Wenger (1991). The study's findings therefore raise important questions for the field of information practices/behavior research, where embodied information practices have until now received relatively little attention. 
Michael Olsson is a senior lecturer in information \& knowledge management in the School of Communication, University of Technology Sydney. He is active in the field of information behavior/practices research with particular interest in embodied and affective information practices. He has also written extensively about a range of conceptual and methodological approaches including practice theory, Foucauldian and critical discourse analysis and Sense-Making.

\section{Ixchel M. Faniel, OCLC Research}

Ixchel Faniel draws from her research that started with studies examining data reuse practices that were meant to inform the preservation of data's meaning through documentation and curation practices that support reuse. She discusses how findings from her reuse studies not only evolved her perspective to studying key practices throughout the data lifecycle, but also grew her understanding of human information behavior and practices.

Ixchel Faniel is a research scientist at OCLC. Current work includes examining how academics manage, share and reuse research data and librarians' experiences designing and delivering supportive research data management programs. Her research has been funded by the National Science Foundation, Institute of Museum and Library Services and National Endowment for the Humanities.

\section{Costis Dallas, University of Toronto}

Costis Dallas is interested in probing the material-semiotic dimensions of the archaeological record and its entanglement with archaeological work as an epistemic "contact zone" between archaeology and information studies. In this panel, he first introduces relationships such as archaeological vs. archival record, provenience vs. provenance, archaeological (post-depositional) context vs. archival bond, archaeological documentation vs. archival representation, archaeological typology vs. classification in information science, object agency vs. digital materiality and archaeological curation vs. digital curation. Second, drawing from earlier information behavior and digital curation models, he introduces a formal conceptualization of archaeological work as cultural-historical information activity which may adequately articulate actual (descriptive) with normative (methods laden) dimensions, as well as human archaeological agency with artefacttool mediation.

Costis Dallas is associate professor and director of the collaborative programs at the Faculty of Information, University of Toronto and research fellow of the digital curation unit, "Athena" Research Centre, Greece. His current research focuses on the theory of digital curation of thing cultures, on archaeological and heritage practices in the pervasive digital environment, and on identity and memory work in social network site interactions around tangible cultural heritage.

\section{Marija Dalbello, Rutgers, the State University of New Jersey}

Archeology is a science of the positive in that it traces and studies what had a physical presence. The relevance of archeological perspectives for information science are in the positivist space - of how mute evidence of texts and artifacts, embedded in the material documentary cultures and material traces, can be interpreted structurally and read as patterned production in time-space, as a formation and in-formation. I first outline the interpretation of presence that focuses on traces through the lens of digital humanities, bibliographic archaeology and media archaeological perspective. All of these carry relevance for the readings of patterned production as evidence, structurally and contextually situating these interpretations in relation to situated contexts of production, use and reuse conforming to a functionalist-structuralist model. I argue that physical presence can provide a launching point for a critical archeological reading of traces in the negative space of presence by surfacing the absence in archeological readings of physical presence and evidence, against the grain. Interventions that focus on the missing picture and the expressions of absence in an information archeological sense highlight the incomplete presence of texts and objects from a critical perspective. I will attach this argument to examples from the context of archivist activism and exemplify how insertions into the past can provide the interpretations in the present and are similarly archaeological in approach.

Marija Dalbello is an associate professor of information science in the School of Communication and Information, Rutgers University. Her teaching and publications focus on the history of knowledge and history of the book.

\section{ACKNOWLEDGEMENTS}

A part of this work has been based upon work from COST Action ARKWORK, supported by COST (European Cooperation in Science and Technology). Faniel acknowledges support from IMLS for the DIPIR project (LG-06-10-014010) and NEH for the SLO-data project (PR-234235). Huvila's work has been supported by the Swedish Research Council Grant 340-2012-5751.

\section{REFERENCES}

Beaudoin, J. E. (2014). A framework of image use among archaeologists, architects, art historians and artists. Journal of Documentation, 70(1), 119-147.

Börjesson, L. (2016). Beyond information policy: Conflicting documentation ideals in extra-academic knowledge making practices. Journal of Documentation, 72(4), 674 - 695.

Dalbello, M. (2013). Digitality, epistolarity and reconstituted letter archives. Information Research 18(3).

Dalbello, M. (2011). A genealogy of digital humanities. Journal of Documentation 67(3), 480-506. 
Dalbello-Lovric, M. (1999). The case for bibliographical archeology. Analytical \& Enumerative Bibliography, 10(1), 1-20.

Dallas, C. (2015). Curating archaeological knowledge in the digital continuum: From practice to infrastructure. Open Archaeology, 1(1), 176-207.

Dallas, C. (2016a). Digital curation beyond the "wild frontier": A pragmatic approach. Archival Science, 16(4), 421-457.

Dallas, C. (2016b). Jean-Claude Gardin on archaeological data, representation and knowledge: Implications for digital archaeology. Journal of Archaeological Method and Theory, 23(1), 305-330.

Dewey, S. H. (2016). (Non-)use of Foucault's Archaeology of Knowledge and Order of Things in LIS journal literature, 1990-2015. Journal of Documentation, 72(3), 454-489.

Faniel, I., Kansa, E., Whitcher Kansa, S., Barrera-Gomez, J., \& Yakel, E. (2013). The challenges of digging data: A study of context in archaeological data reuse. Proceedings of the Joint Conference on Digital Libraries (JCDL), 295-304.

Faniel, Ixchel M. and Yakel, Elizabeth (2017). Practices do not make perfect: Disciplinary data sharing and reuse practices and their implications for repository data curation. In Curating Research Data, Volume One: Practical Strategies for Your Digital Repository (pp. 103-126). Chicago, Illinois: Association of College and Research Libraries.

Huhtamo, E. \& J. Parikka, eds. (2011). Media archaeology: Approaches, applications, and implications. University of California Press.

Huvila, I. (2006). The ecology of information work - A case study of bridging archaeological work and virtual reality based knowledge organisation. Diss. Åbo Akademi University.

Huvila, I. (2016a). Awkwardness of becoming a boundary object: Mangle and materialities of reports, documentation data and the archaeological work. The Information Society, 32(4), 280297.
Huvila, I. (2016b). 'if we just knew who should do it,' or the social organization of the archiving of archaeology in Sweden. Information Research, 21(2).

Khazraee, E. (2013). Information recording in archaeological practice: A socio-technical perspective. In iConference 2013, February 12-15, 2013 Fort Worth, TX.

Lave, J. and Wenger, E. Situated learning. Cambridge: Cambridge University Press, 1991.

Mak, B. (2014). Archaeology of a digitization. JASIST, 65(8), 1515-1526.

MacGregor, G. Making sense of the past in the present: A sensory analysis of carved stone balls. World Archaeology 1999, 31(2): 258-271.

Olsson, M. (2016). Making sense of the past: The embodied information practices of field archaeologists. Journal of Information Science, 42(3), 410-419.

Parikka, J. (2012). What is media archaeology? Cambridge: Polity.

Radford, G. P., Radford, M. L., \& Lingel, J. (2012). Alternative libraries as discursive formations: Reclaiming the voice of the deaccessioned book. Journal of Documentation, 68(2), 254267.

Seymour, D. J. (2009). Introduction: International perspectives on the archaeological grey literature. Grey Journal, 5(2), 64-66.

Tudhope, D., Binding, C., Jeffrey, S., May, K., \& Vlachidis, A. (2011). A STELLAR role for knowledge organization systems in digital archaeology. Bulletin of American Society for Information Science and Technology, 37(4), 15-18.

Vlachidis, A., \& Tudhope, D. (2015). A knowledge-based approach to information extraction for semantic interoperability in the archaeology domain. JASIST, 67(5), 1138-1152. 